\title{
Cytotoxic and antimicrobial activities of ethyl acetate extract of mangrove plant Scyphiphora hydrophyllacea C. F. Gaertn- Associated fungi
}

\author{
Dian Handayani ${ }^{1 *}$, Neny sandrawati ${ }^{1}$, Rustini Ruslan ${ }^{1}$, Oga Nestianda ${ }^{2}$, Anzharni Fajrina ${ }^{2}$, Trina Ekawati Tallei ${ }^{3}$ \\ ${ }^{1}$ Sumatran Biota Laboratory/Faculty of Pharmacy, University of Andalas, Kampus Limau Manis, Padang, West Sumatera, Indonesia \\ ${ }^{2}$ School of Pharmacy, Padang, Indonesia \\ ${ }^{3}$ Department of Biology, Faculty of Mathematics and Natural Sciences, Sam Ratulangi University, Kampus UNSRAT Kleak, Manado, 95115, Indonesia
}

\begin{tabular}{l}
\hline ARTICLE INFO \\
\hline Received on: 02/02/2019 \\
Accepted on: 05/05/2019 \\
Available online: 05/06/2019
\end{tabular}

Key words:

Antimicrobial activity, cytotoxic activity, mangrove, Penicillium chrysogenum, Scyphiphora hydrophyllacea.

\begin{abstract}
Association between mangrove plants with fungi has been explored for many biological activities. The purpose of this study was to determine the antimicrobial and cytotoxic activities of endophytic fungi isolated from mangrove plants Scyphiphora hydrophyllacea C. F. Gaertn. The isolation of endophytic fungus from the mangrove has been carried out by the direct planting method on Sabouraud Dextrose Agar medium. Eleven fungal isolates were recovered and purified. The isolates were cultivated on the rice medium for 1 month and extracted using ethyl acetate. Eleven ethyl acetate extracts were screened for cytotoxic activity by Brine Shrimp Lethality Test method and 3-(4,5-dimethylthiazol2-yl)-2,5-diphenyltetrazolium bromide assay and for antimicrobial activity toward some human pathogenic microbes. The results showed that five $(45.5 \%)$ isolates of endophytic fungi had antimicrobial activity against the growth of Staphylococcus aureus, Escherichia coli, and Candida albicans with a diameter from 9.1 to $21 \mathrm{~mm}$. Furthermore, four extracts $(36.4 \%$ ) were cytotoxic (cell viability $<50 \%$ ) against T47D cells. Isolate ADSH2 which exhibited the highest cytotoxic activity was identified molecularly as Penicillium chrysogenum. The results of this study indicate that the ethyl acetate of endophytic fungi associated with Scyphiphora hydrophyllacea has the potential to be developed as antimicrobial and anticancer compounds.
\end{abstract}

\section{INTRODUCTION}

Endophytic fungi from the mangrove plant are categorized as the second biggest ecology after marine endophyte fungi (Khrueayu and Apiradee, 2012). The host and endophytic plants have symbiotic mutualism in which the host plants provide nutrients for endophytes and function as a shelter, while endophytes produce bioactive substances to increase host growth and competitiveness in their natural habitat (Sun et al., 2014). Endophytes can produce various bioactive compounds that are useful in the research and can be used in the development of anticancer and antimicrobial drugs (Li et al., 2018).

\footnotetext{
"Corresponding Author

Dian Handayani, Laboratory of Sumatra Biota, Faculty of Pharmacy,

Andalas University, Padang, Indonesia.

E-mail:dianhandayani@phar.unand.ac.id
}

The endophytic fungi from mangroves are reported to produce various types of secondary metabolites (Firáková et al., 2007). The natural products compound produced by the endophytic fungi from mangroves has been screened for antimicrobial agents against many pathogenic bacteria and fungi and also for cytotoxic effect in many cell cancer lines. This research was focused on determining the potency of fungal extracts isolated from the mangrove plant $S$. hydrophyllacea C. F. Gaertn collected from West Sumatra, Indonesia in continuation with our research on bioactive natural compounds derived from marine and mangrove origins (Handayani and Artasasta 2017; Handayani and Aminah 2017; Handayani et al., 2015a; 2015b; 2016; 2017; 2018; 2019).

\section{MATERIALS AND METHODS}

\section{Sample preparation}

Mangrove plant was collected from Teluk Pandan, Bungus ( $\left.1^{\circ} 1^{\prime} 54.17^{\prime \prime} \mathrm{S} ; 100^{\circ} 25^{\prime} 42.3^{\prime \prime} \mathrm{E}\right)$ West Sumatra, Indonesia. 
The leaves, bark, and roots of S. hydrophyllacea C. F. Gaertn were taken as much as $\pm 100 \mathrm{~g}$, put into the sterile plastic bag and then transferred to the laboratory of Sumatran Biota, University of Andalas, Padang, West Sumatera, Indonesia.

Isolation, cultivation, and extraction of mangrove plant $S$. hydrophyllacea C. F. Gaertn-associated fungi

The leaves, bark, and roots were surface-sterilized by rinsing with running water for 10 minutes, and then rinsed with ethanol $70 \%$ for 1 minute. Thereafter, the samples were soaked in bleach solvent $(\mathrm{NaOCl} 5.3 \%)$ for 5 minutes and rinsed again with ethanol $70 \%$ for 30 seconds. The isolation process was conducted under Laminar Air Flow. The sterile samples were cut into small pieces. Each piece was inoculated on Sabouraud Dextrose Agar (SDA) medium and incubated at $25^{\circ} \mathrm{C}$ (3-5 days). The fungal colonies which grew on SDA medium then purified gradually. The colonies that have different shape and colors regarded as different isolates.

Pure isolates of endophytic fungi were cultivated in 100 -g rice medium and then incubated at $25^{\circ} \mathrm{C}$ for 30 days. The cultivation process was conducted based on Kjer et al. (2010). The extraction method of the secondary metabolite has been carried out following the previous research (Handayani et al., 2018).

\section{Testing for antimicrobial activity}

Staphylococcus aureus ATCC 25923, Escherichia coli ATCC 25922, and Candida Albicans, which are used as test microbes, were obtained from the Microbiology Laboratory, M. Djamil General Hospital Padang, West Sumatra, Indonesia. Testing for this activity was carried out by the agar diffusion method in the concentration 5, 3, and $1 \mathrm{mg} / \mathrm{ml}$ in dimethyl sulfoxide (DMSO). Tetracyclin $\mathrm{HCl}(300 \mu \mathrm{g} / \mathrm{ml})$ (PT Phapros, Indonesia), and ketoconazole $(20 \mathrm{mg} / \mathrm{ml})$ (PT Kimia Farma, Indonesia) in distilled water were used as a positive control. The antimicrobial screening was conducted based on the method described previously (Handayani et al., 2015a; 2017; 2018).

\section{Screening for cytotoxic activity}

\section{BSLT method}

The nauplii of brine shrimp (Artemia salina L.: Artemiidae) were used for cytotoxic activity assay. The eggs were hatched in $500 \mathrm{ml}$ of filtered seawater under constant aeration for 48 hours at $27^{\circ} \mathrm{C} \pm 2{ }^{\circ} \mathrm{C}$. After hatching, active nauplii free from eggshells were collected and used for the assay. The final concentrations of the extracts used in this assay were 1,000, 100, and $10 \mu \mathrm{g} / \mathrm{ml}$ in triplicate. As negative controls are used filtered seawater and DMSO. Cytotoxic activity was determined based on the $\mathrm{LC}_{50}$ value determined using the curve method based on probit analysis (Meyer et al., 1982).

\section{MTT assay}

Two cell lines, T47D as human ductal breast epithelial tumor cell line, and Vero as normal cell line were prepared for cytotoxic assay. All the cell lines were obtained from the Laboratory of Parasitology at Gajah Mada University, Yogyakarta, Indonesia. The stages of the research method for 3-(4,5-dimethylthiazol-2yl)-2,5-diphenyltetrazolium bromide (MTT) assay have been carried out as written in the research that we have done before (Handayani et al., 2017; 2018; Permanasari et al., 2013).

\section{Molecular identification of mangrove-associated fungi}

The characterization of endophytic fungi was performed in macroscopic examination included surface, colors, and the edge of each colony. The molecular identification was performed out using internal transcribed spacer (ITS) DNA barcode with special primer pairs for fungi, by following the procedures carried out by Handayani et al. (2019). The ITS region covers internal transcribed spacer 1, 5.8S ribosomal RNA, internal transcribed spacer 2, and large subunit ribosomal RNA. PCR product was sequenced in first Base, Malaysia. The sequencing result was processed following the procedure performed by Tallei and Kolondam (2015) and subjected to BLAST (https://blast.ncbi.nlm.nih.gov/ Blast.cgi) at NCBI (https://www.ncbi.nlm.nih.gov/) for species identification. The identification result was further verified using pairwise sequence identification at MycoBank (http://mycobank. org). Analysis of the phylogenetic tree is formed by arranging the neighbor-joining tree method with a value of 1,000 bootstrap replicate by using MEGA 7.0 developed by Kumar et al. (2016).

\section{RESULTS AND DISCUSSION}

Endophytes are a group of microorganisms that live in healthy plant tissues without causing negative impacts on host plants. The types of endophyte mainly include fungal, bacterial, and actinomycetes endophytes. Based on previous research reports, endophytic an important source producer of natural compounds for coexistence between endophyte and host plants create complex relationships, so the endophyte is able to produce the same bioactive secondary metabolites by plants, such as antimicrobial and cytotoxic agents (Li et al., 2018). Endophytes can also be found in mangrove plants tissue.

\section{Antimicrobial activity of fungal extracts}

In this study, 11 pure endophytic fungi have been isolated from the mangrove $S$. hydrophyllacea C. F. Gaertn. The leaves contained most of the endophytic fungi than bark and root. The isolation of endophytic fungi from the different part of the host plant can obtain different fungal species. Endophyte which grows in the stressful condition area experiences many physical and chemical challenges, so they become the potential sources of bioactive substances (Raghukumar, 2008). All of the isolates were distinguished with each other based on the difference of color, surface, and the edge of the colony. Each fungal isolates was cultivated in $100 \mathrm{mg}$ rice medium for 30 days. Some factors can give effects in the growth process of microorganisms, such as inoculum size, nutrition ingredients in the substrate, water content, $\mathrm{pH}$, and temperature. After being cultivated, the fungal isolates were extracted using ethyl acetate solvent to obtain the secondary metabolite.

The screening of antimicrobial activity of all fungi extracts was conducted against some pathogenic microorganisms, such as $S$. aureus, E. coli, and C. albicans. Based on this screening result, four ethyl acetate extracts of endophytic fungi inhibited the growth of $S$. aureus with a diameter zone of $>9 \mathrm{~mm}$ (at concentration 5\%), four extracts inhibited E. coli and two extracts inhibited the growth of $C$. albicans. The fungal isolates with 
code DNSH3 exhibited good activities against all the reference pathogenic microorganisms with a diameter of inhibitory zone 21 , 21, and $10.2 \mathrm{~mm}$, respectively (Fig. 1).

\section{Cytotoxic activity of fungal extracts}

The Brine Shrimp Lethality Test (BSLT) method was used as a preliminary test for cytotoxic activity screening. The results showed that four isolates of the fungus $(36.4 \%$ of total fungal isolates) have cytotoxic activity below $100 \mu \mathrm{g} / \mathrm{ml}$. The cytotoxic isolates were ADSH1, ADSH2, DNSH2, and DNSH3. The isolate which showed the highest cytotoxic activity was ADSH2 with LC $_{50}$ of $45.6 \mu \mathrm{g} / \mathrm{ml}$ (Fig. 2). According to Meyer et al. (1982), the extracts are considered very toxic when it has an $\mathrm{LC}_{50}$ value $<30 \mu \mathrm{g} / \mathrm{ml}$, and toxic if it has a value of $\mathrm{LC}_{50}$ value $30-1,000 \mu \mathrm{g} / \mathrm{ml}$.

Further testing on the cytotoxic test was conducted by MTT assay. This assay is a popular method to assess cytotoxicity and cell viability of the living cell. The test principle is an enzymatic reduction of the lightly colored tetrazolium salt to its formazan, whereas changing the color solution in microtiter plate from intense purple to blue color. Absorbance measurements are obtained at the end of the assay (Grela et al., 2018; Stockert et al., 2012). The determination of $\mathrm{IC}_{50}$ value begins by determining the percentage viability of cancer cells in the culture medium after adding endophytic fungi extract with a concentration of $100 \mu \mathrm{g} /$ $\mathrm{ml}$.

The fungal extract of ADSH3, KBSH1, KBSH2, $\mathrm{KBSH} 3$, and DNSH2 are the extracts with the lowest percentage of viability $(<50 \%)$ against T47D cancer cells. The EtOAc extracts of DNSH2 was the best selectively cytotoxic on T47D ductal breast cancer cells (the percentage of viability of $11.75 \%$ ), and has low toxicity on Vero normal cells (the percentage of viability of $80.61 \%$ ) (Fig. 3).

\section{Molecular identification of selected fungal isolates}

The isolate ADSH2, one of the potential fungi in producing cytotoxic agent, was then identified morphologically and molecularly. The ITS region was chosen for the molecular identification. The colony of isolate ADSH2 was brown-colored with wavy edges (Fig. 4). The BLAST identification showed that isolate ADSH2 has $100 \%$ identity with Penicillium chrysogenum isolate AYMA5 (Accession number: MK643348) with $E$ value 0.0 . The closer the $E$-value is to zero, the more significant the match is considered to be. Using pairwise sequence identification at MycoBank, isolate ADSH2 has 100\% similarity with Penicillium chrysogenum isolate 2OI2F1T (Accession number: KY524459). The phylogenetic tree was constructed by MEGA (version 7.0) using a neighbor-joining $p$-distance algorithm method with a bootstrap value of 1,000 (Fig. 5). The tree shows the position of the sample together with the species it belongs to.

The fungus $P$. chrysogenum has been explored in other previous research. A novel chaetoglobosin, Penochalasin I, was isolated from the culture of endophytic fungus $P$. chrysogenum inhabiting the vein of mangrove Myoporum bontioides in Guangdong Province, China. This compound displayed cytotoxic activities toward MDA-MB-435 and SGC-7901 cell lines $\left(\mathrm{IC}_{50}<\right.$
$10 \mu \mathrm{M})$ (Huang et al., 2018). New polyketides, penicichrsogenins A-L, were isolated from the solid substrate fermentation culture of $P$. chrosogenum MT-12, an endophytic fungus from a Chinese club moss (Huperzia serrata). All of the isolated compounds were able to inhibit the production of nitric oxide in lipopolysaccharidestimulated RAW264.7 macrophage cells $\left(\mathrm{IC}_{50}=17.5-98.4 \mu \mathrm{M}\right)$ (Qi et al., 2017).

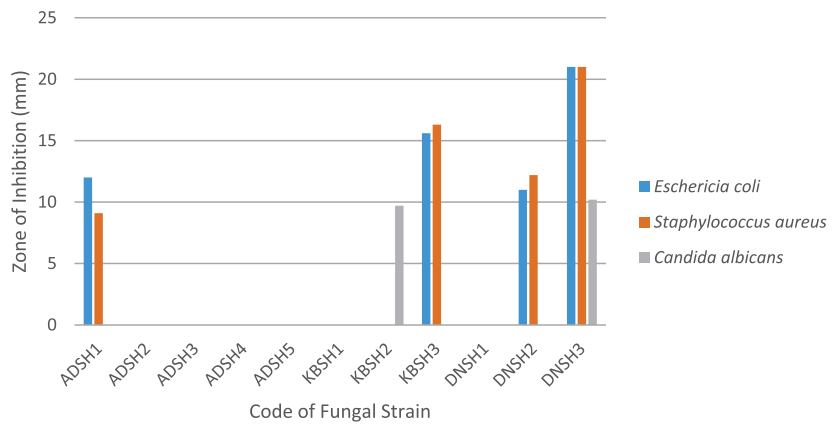

Figure 1. The antimicrobial activity of ethyl acetate extract of endophytic fungi isolated from S.hydrophyllacea.

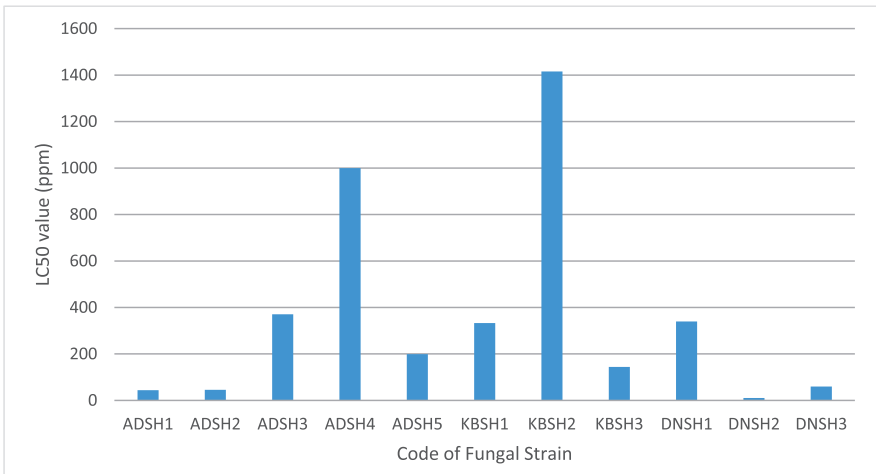

Figure 2. The cytotoxic activity of ethyl acetate extract of endophytic fungi isolated from S. hydrophyllacea.



Figure 3. The cytotoxic activity of ethyl acetate extract of endophytic fungi isolated from S. hydrophyllacea. 


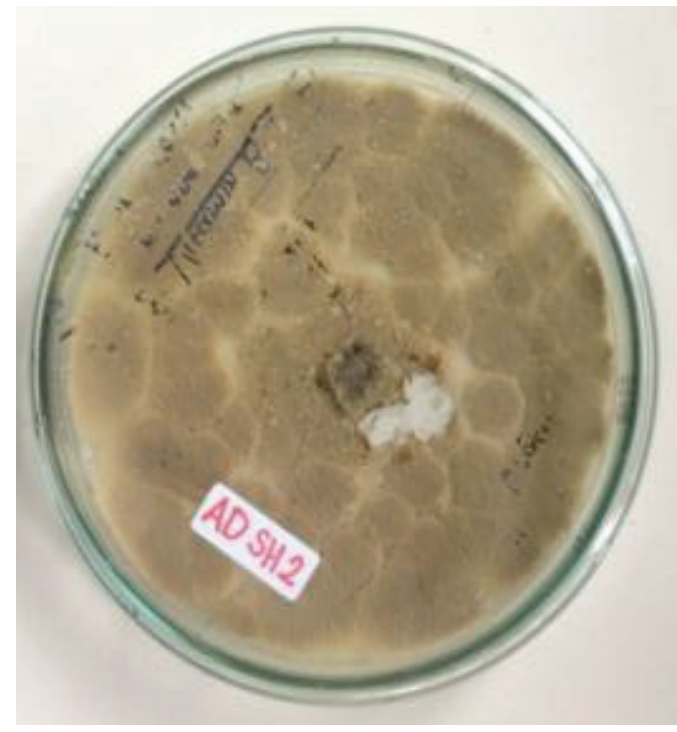

Figure 4. Macroscopic characteristics from endophytic fungus isolate ADSH2 of Scyphiphora hydrophyllacea C. F. Gaertn.

100

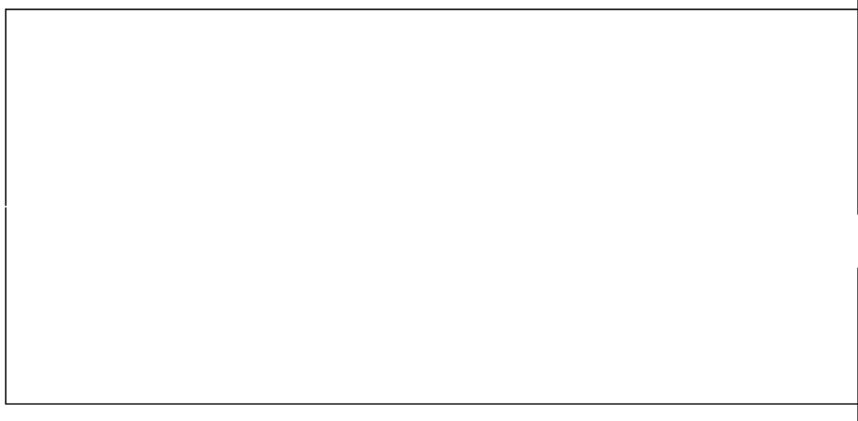

LT558859.1 Penicillium rubens

JN986756.1 Penicillium commune strain DHMJ04

MG596658.1 Penicillium citrinum strain NW-62

KP994293.1 Penicillium sp. G2Pb

65

GU723445.1 Penicillium commune strain G20-23

MF061782.1 Penicillium sp. strain SCAU120

HQ443258.1 Penicillium sp. SFRh11

LT558858.1 Penicillium rubens

KX266831.1 Penicillium chrysogenum strain SCSIO

$\mathrm{ADSH} 2$

HF546386.1 Penicillium chrysogenum

JF731255.1 Penicillium chrysogenum isolate BP2T3

JN368454.1 Penicillium chrysogenum isolate BP3T1

\begin{tabular}{|l} 
1st BASE 27935271861 ITS1F.ab1 \\
MH171489.1 Aspergillus flavus isolate TJM-F7 \\
MF685314.1 Aspergillus flavus strain NB19 \\
GU172440.1 Aspergillus flavus isolate UPM A8 \\
LN482514.1 Aspergillus flavus \\
KY827336.1 Aspergillus flavus strain SCAU006 \\
LN482492.1 Aspergillus oryzae \\
MG596623.1 Aspergillus nomius strain NW-27 \\
MG437005.1 Aspergillus oryzae strain MF13
\end{tabular}

Figure 5. The phylogenetic tree inferred using the neighbor-joining method of ITS sequence of endophytic fungus isolate ADSH2 of Scyphiphora hydrophyllacea C F. Gaertn and its allied taxa. 


\section{CONCLUSION}

Based on the results of this study, it can be concluded that the endophytic fungi from mangrove plants $S$. hydrophyllacea C. F. Gaertn are the potential source for antibiotics and anticancer agents. The result indicated that the isolate ADSH2 shows the potential to be used as a source of new anticancer compounds in the future. However, further research needs to be done, for the stages of purification and elucidation of the structure of antimicrobial and cytotoxic compounds produced by the fungi.

\section{ACKNOWLEDGMENTS}

The work was supported by BOPTN of Andalas University, Padang, Indonesia, in the project of "Hibah Klaster Riset Guru Besar,” No. 15/UN.16.17/PP.RGB/LPPM/2018.

\section{CONFLICT OF INTEREST}

There are no conflicts of interest declared by the authors.

\section{REFERENCES}

Firáková S, Šturdíková M, Múčková M. Bioactive secondary metabolites produced by microorganisms associated with plants. Biologia, 2007; 62(3):251-7.

Grela E, Joanna K, Agnieszka G. Current methodology of MTT assay in bacteria - a review. Acta Histochem, 2018; 120:303-11.

Handayani D, Ananda N, Artasasta MA, Ruslan R, Fadriyanti $\mathrm{O}$, Tallei TE. Antimicrobial activity screening of endophytic fungi extracts isolated from brown algae Padina sp. J Appl Pharm Sci, 2019; 9(03):09-13; doi: 10.7324/JAPS.2019.90302

Handayani D, Harrizul R, Rizka M, Netty S, Roslaili R, Triana H. Antimicrobial and cytotoxic activities of endophytic fungi isolated from mangrove plant Sonneratia alba Sm. J Appl Pharm Sci, 2018; 8(02):049_ 53.

Handayani D, Rivai H, Hutabarat M, Rasyid R. Antibacterial activity of endophytic fungi isolated from mangrove plant Sonneratia griffithii Kurz. J Appl Pharm Sci, 2017; 7(04):209-12.

Handayani D, Artasasta MA. Antibacterial and cytotoxic activities screening of symbiotic fungi extracts isolated from marine sponge Neopetrosia chaliniformis AR-01. J Appl Pharm Sci, 2017; 7(05):066-9.

Handayani D, Aminah I. Antibacterial and cytotoxic activities of ethyl acetate extract of symbiotic fungi from West Sumatra marine sponge Acanthrongylophora ingens. J Appl Pharm Sci, 2017; 7(02):237-40.

Handayani D, Ornando R, Rustini R. Antimicrobial activity screening of symbiotic fungi from marine sponge Petrosia nigrans collected from South Coast of West Sumatra Indonesia. Int J Pharmacogn Phytochem Res, 2016; 8(4):623-5.

Handayani D, Ahdinur RF, Rustini R. Antimicrobial activity of endophytic fungi from marine sponge Haliclona fascigera. J Appl Pharm Sci, 2015a; 5(10):154-6.

Handayani D, Sandrawaty N, Murniati M, Regina R. Screening of endophytic bacteria isolated from marine sponge Haliclona fascigerafor inhibition against clinical isolates of Methicillin-Resistant Staphylococcus aureus (MRSA). J Appl Pharm Sci, 2015b; 5(9):139-42.

Huang S, Haiyan C, Achunyuan L. Bioactive chaetoglobosins from the mangrove endophytic fungus Penicillium chrysogenum. Marine Drugs, 2018; 14(10):172.

Kumar S, Stecher G, Tamura K. MEGA7: molecular evolutionarygenetics analysis version 7.0 for bigger datasets. Mol Biol Evol, 2016; 33(7):1870-4.
Sun JF, Lin X, Zhou XF, Wan J, Zhang T, Yang B, Yang XW, Tu Z, Liu Y. Pestalols A-E, new alkenyl phenol and benzaldehyde derivatives from endophytic fungus Pestalotiopsis $s p$. AcBC2 isolated from the Chinese mangrove plant Aegiceras corniculatum. J Antibiot, 2014; 67(6):451-7.

Khrueayu D, Apiradee P. Antifungal activity of bioactive compound from endophytic fungi isolated from mangrove leaves. First Mae Fah Luang University International Conference, Burapha University, Thailand, 2012

Kjer J, Debbab A, Aly AH, Proksch P. Methods for isolation of marine-derived endophytic fungi and their bioactive secondary products. Nat Protocols, 2010; 5(3):479-90.

Li S, Xuan Z, Xiang W, Chang Z. Novel natural compounds from endophytic fungi with anticancer activity. Eur J Med Chem, 2018; $156: 316-43$.

Meyer BN, Ferrigni NR., Putman JE, Jacobsen DE, Nichols DE, Mc Laughlin JL. Brine Shrimps L. A convenient general bioassay for active plant constituent. Planta Media, 1982; 45:31-4.

Permanasari P, Hertiani T, Yuswanto A. Immunomodulatory effect of Massoia bark extracts and the cytotoxicity activity against pericarps of Mangosteen (Garcinia mangostana Linn.) on WiDr cells and interaction study of alpha-mangosteen to IKK and VEGF based on molecular docking. ISCC, 2013; 4(1):470-6.

Qi B, Xiao L, Ting M, Shan-Shan L, Juan W, Xiao-Ping S. Nitric oxide inhibitory polyketides from Penicillium chrysogenum MT-12, an endophytic fungus isolated from Huperzia serrata. Fitoterapia, 2017; 123:35-43.

Raghukumar C. Marine fungal biotechnology: an ecological perspective. Fungal Diversity, 2008; 31:19-35.

Stockert JC, Blazquez-Castro A, Canete M, Horobin RQ, Villanueva A. MTT assay for cell viability: intracellular localization of the formazan product is in lipid droplets. Acta Histochem, 2012; 114(8):78596

Tallei TE, Kolondam BJ. DNA barcoding of Sangihe nutmeg (Myristica fragrans) using matK gene. Hayati J Biosci, 2015; 22(1):41-47; doi: 10.4308/hjb.22.1.41

How to cite this article:

Handayani D, Sandrawati N, Nestianda O, Ruslan R, Fajrina A, Tallei TE. Cytotoxic and antimicrobial activities of ethyl acetate extract of mangrove plant Scyphiphora hydrophyllacea C. F. Gaertn-Associated fungi. J Appl Pharm Sci, 2019; 9(06):075-079. 